\title{
Fire-eater's pneumonitis
}

\author{
E. Grossi1, E. Crisanti2, G. Poletti3, V. Poletti4
}

ABSTRACT: Fire-eater's pneumonitis. E. Grossi, E. Crisanti, G. Poletti, V. Poletti.

The authors report a case of acute respiratory failure that fulfils the diagnostic criteria for fire-eater's pneu- monitis; pathological features, usually described only in experimental works on animals, are also discussed.

Monaldi Arch Chest Dis 2006; 65: 1, 59-61.

Keywords: Fire-eater's pneumonitis, Fire-eater's lung, Kerdan-pyrofluids aspiration, Necrotizing acute bronchiolitis necrotizing acute fibrinous pneumonia pyrofluid related, Fire-eater's pneumonia experimental works.

1 Department of Internal Medicine, Santa Maria delle Croci Hospital, Ravenna,

2 Department of Pathology, Santa Maria delle Croci Hospital, Ravenna,

3 Clinical Pathology Department, Santa Maria delle Croci Hospital, Ravenna,

4 Department of Diseases of the Thorax, GB Morgagni Hospital, Forli, Italy.

Correspondence: Dr. Enzo Grossi, Seconda Divisione Medica, Ospedale Civile Santa Maria delle Croci, Viale Randi 5, 48100 Ravenna Italy; e-mail: enzogrossi@libero.it

\section{Introduction}

Fire-eater's pneumonitis, also known as 'fireeater's lung', is an acute inflammatory response of the lungs to the accidental aspiration, during the show, of 'pyrofluids' or kerdan [1-9]. Kerdan is composed of petroleum-distilled products like toluene, xylene, ethilbenzene which differ from kerosene composition. Kerdan is characterised by its reduced viscosity and, unfortunately, by its rapid diffusion throughout the bronchial tree after sudden accidental aspiration [7]. Histological findings (not easily available in the literature) show necrotising acute bronchiolitis and necrotising acute fibrinous pneumonia, as previously reported in experimental models [10]. Despite the severe initial presentation, 'fire-eater's lung' usually has a favourable evolution with 'restitutio ad integrum' of pulmonary functions [7].

\section{Case report}

A 31-year-old non-smoker, previously healthy, fire-eating female was admitted to the emergency department for dyspnea, cough, hemopthysis, chest pain, and a body temperature of $39.4^{\circ} \mathrm{C}$. Blood pressure was $110 / 70 \mathrm{mmHg}$, the heart rate 130 beats/min, and the respiratory rate was 30 breaths/min.

She reported that symptoms had occurred soon after the flame-blowing act, since she accidentally aspirated a small amount of kerdan during the show.

Chest radiogram and high resolution $\mathrm{CT}$ scan (HRCT) revealed patchy bilateral alveolar infiltrates in the middle and lower parts of both lungs. A bilateral pleural effusion was also present (fig. 1).
The cell blood count revealed elevated WBCs (16.400/microL) with a left shift, C-reactive protein was $27.1 \mathrm{mg} / \mathrm{dl}$, while serum electrolytes, hepatic and renal function tests were normal. Arterial blood gases (ABGs) on room air were as follows: $\mathrm{pH}$ 7.40, $\mathrm{PaCO}_{2} 34.7 \mathrm{mmHg}, \mathrm{PaO}_{2} 68$ $\mathrm{mmHg}$.

Bronchoscopy under general anaesthesia using a rigid bronchoscope and a fiberoptic bronchoscope with bronchoalveolar lavage (BAL) and fluoroscopic guided pulmonary biopsies in the left lower lobe were performed six days after kerdan ingestion. Macroscopic examination of the airways showed a diffuse inflammation of the bronchial mucosa. BAL profile showed an increase of total cells $(880,000$ cells $/ \mathrm{mL})$. The differential cell counts was: $77 \%$ neutrophils, $14 \%$ macrophages, $8 \%$ lymphocytes, and $1 \%$ eosinophils. Stains cultures and direct immunofluorescent tests for microorganisms (bacteria, mycobacteria, Legionella pneumophila, fungi, Cytomegalovirus, Syncytial Respiratory Virus, Herpes Simplex Viruses type I and II, Adenovirus, Influenza and Parainfluenza Viruses) were performed and proved to be negative. Oil red stain on BAL fluid slides showed small drops both free and in the cytoplasm of macrophages. Twelve lung biopsies were processed. In Hematoxylin-Eosin preps a necrotizing acute and fibrinous pneumonia was evident (fig. 2). The bronchiolar wall also was diffusely infiltrated by neutrophils and thickened for interstitial edema. The epithelium was necrotic and sloughing. Specials stains for bacteria, mycobacteria and fungi (Brown-Brenn, ZiehlNeelsen, Grocott) were negative.

The patient was treated with broad-spectrum antibiotics, and she received supplemental $\mathrm{O}_{2}$ for a 


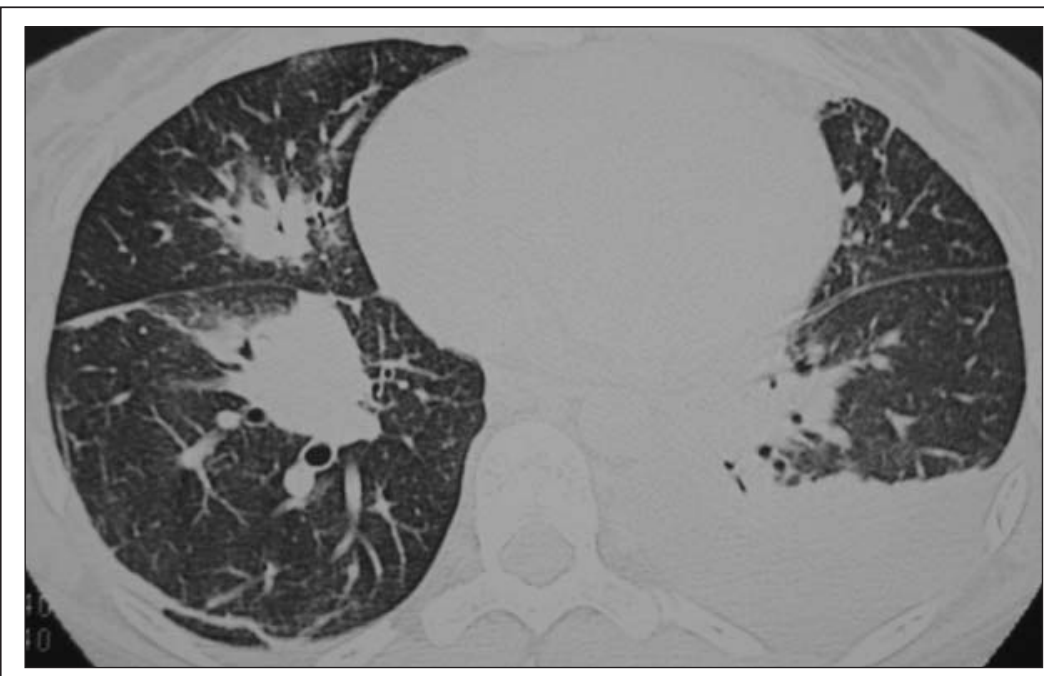

Fig. 1. - HRCT at the lung bases. Patchy areas of alveolar consolidation and bilateral pleural effusion are evident.

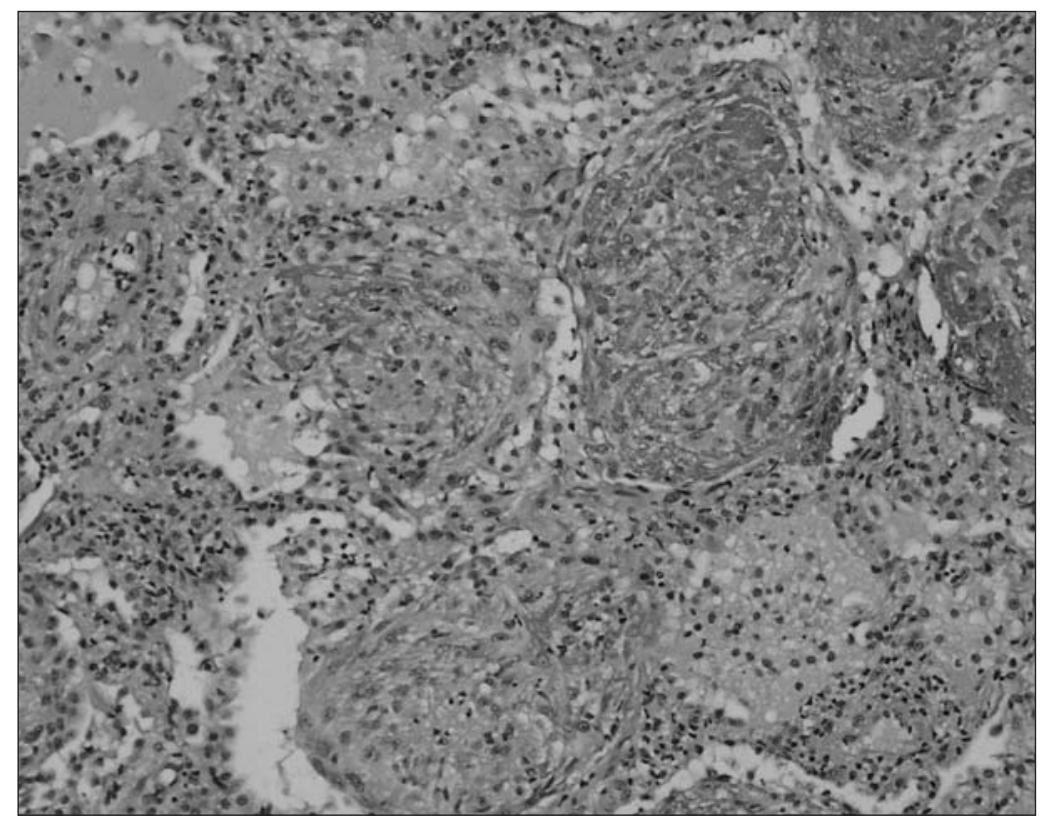

Fig. 2. - Neutrophils in the alveolar spaces are mixed with chronic inflammatory cells, balls of fibrinous exudate, and early intralveolar organisation. H\&E x 100.

period of 4 days. Respiratory symptoms disappeared within 72 hours, fever persisted for 7 days. Chest X-ray examination showed a complete resolution of pulmonary abnormalities within 20 days.

\section{Discussion}

Since the first work published in 1971 [9], only a few case reports and short series of fire-eater's pneumonitis have been described in literature, with little information about the radiologic and histopathologic findings, or functional sequelae. All the cases described in the literature present the same clinical profile: intense chest or pleuritic pain, acute dyspnea, cough, and fever, all appearing a few hours after inhalation. HRCT findings usually reveal patchy bilateral alveolar infiltrates (sometimes including cavities) with pleural effusion [7]. Two works describe accurately the BAL findings $[7,8]$. The pathological features are well described in experimental works on dogs and rats given kerosene intratracheally [10].

Papers dealing with animal models of the disorder show that the small airways are predominantly affected [10]. One hour after kerosene administration, intraalveolar edema and haemorrhage were observed, with the bulk of the edema in subpleural air spaces or in air spaces adjacent to larger bronchi or larger blood vessels. Since these correspond to the regions where connective tissue is prevalent, the authors postulate: i) the lung interstitium is the most important site of damage; ii) the triggering of the inflammatory reaction is more important than the direct action of kerosene on surface tension forces [10]. Dogs killed one week after kerosene instillation showed notable resolution of the inflammatory process, with focal lesions involving the small airways. The pathological features show a range of changes from slight bronchiolitis obliterans to complete obstruction of the lumen by regenerating epithelial cells, macrophages, and fibroblasts. In animals killed two weeks after instillation of hydrocarbon, the lungs had returned almost to normal, with some small airways still interested by bronchiolitis obliterans, surrounded by local atelectasis [10].

Our case fulfils the clinical, radiological, pathological and laboratory findings of fire-eaters's pnemonitis: in particular microbiological analyses, including bacteria, Legionella, fungi, viruses, and Mycobacterium tuberculosis, were negative $[7,8]$.

Histological findings in lung tissue obtained one week after ingestion of pyrofluid show a necrotising acute bronchiolitis and necrotising acute fibrinous pneumonia, according to the features previously reported in experimental models. Interestingly in this case small drops of OIL RED positive material were identified in alveolar spaces probably because kerdan mixed to other pyrofluids was used.

Fire-eater's pneumonia, despite the severe initial clinical symptoms and radiological presentation, usually has a favourable evolution with 'restitutio ad integrum' of pulmonary functions as observed in this case. As shown in experimental works [10], this demonstrates the possibility of complete resolution of the bronchiolar and alveolar damage, even in presence of substance loss and parenchymal necrosis.

In our report the histological findings of fireeater's lung are reported in detail: in the literature [1-9] this data seems not to be easily available. 


\section{References}

1. Brander PE, Taskinen E, Stenius-Aarniala B. Fireeater's lung. Eur Respir J 1992; 5: 112-114.

2. Bohrer H, Koelz AM. Fire eater's lung (hydrocarbon pneumonitis). Schweiz Med Wochenschr 1994; 124: 362-367.

3. Ewert R, Kern F, Mutze S, Witt C. Aspiration of petroleum by a "fire-eater." Pneumologie 1995; 49: 388-390.

4. Birolleau S, Belleguic C, Lena H, Chemery L, Delaval P. Fire-eater's lung: report of six cases. Rev Pneumol Clin 1999; 55: 27-29.

5. Franquet T, Gomez-Santos D, Gimenez A, Torrubia S, Monill JM. Fire eater's pneumonia: radiografic and CT findings. J Comput Assist Tomogr 2000; 24: 448-450.

6. Haas C, Lebas FX, Le Jeunne C, Lowenstein W, Du- rand $\mathrm{H}$, Hugues FC. Pneumopathies caused by inhalation of hydrocarbons: apropos of 3 cases. Ann Med Interne (Paris) 2000; 151: 438-447.

7. Gentina T, Tillie-Leblond I, Birolleau S, et al. Fireeater's lung: seventeen cases and a review of the literature. Medicine 2001; 80: 291-297.

8. Burkhardt O, Merker H-J, Shakibaei M, Lode H. Electron microscopic findings in BAL of a fire-eater after petroleum aspiration. Chest 2003; 124: 398-400.

9. Gerbeaux J, Couvreur J, Tournier G, Lesage B. Une cause rare de pneumatocele chez l'enfant: L'ingestion d'hydrocarbures (kerdane). Ann Med Interne (Paris) 1971; 122: 589-596.

10. Scharf S.M, Prinsloo I. Pulmonary mechanics in dogs given different doses of kerosene intratracheally. Am Rev Respir Dis 1982; 126: 695-700.

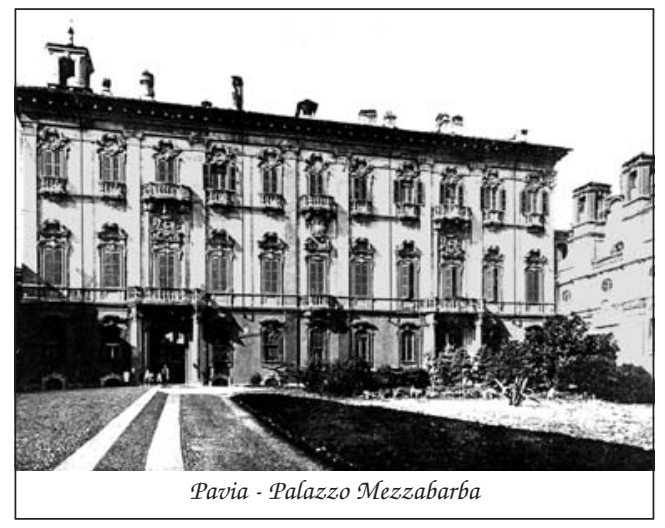

